\title{
Azerbaijan's Current and Potential Comparative Advantage: An Exploratory Study
}

\author{
Lal K. Almas ${ }^{1} \&$ Nazim U. Hajiyev ${ }^{2}$ \\ ${ }^{1}$ Department of Agricultural Sciences, West Texas A\&M University, Canyon, TX, USA \\ ${ }^{2}$ Research Institute for Economic Studies, Azerbaijan State Economic University, Baku, Azerbaijan \\ Correspondence: Lal K. Almas, Department of Agricultural Sciences, West Texas A\&M University, Canyon, TX \\ 79016, USA. Tel: 1-806-651-2552. E-mail: lalmas@wtamu.edu
}

\author{
Received: June 11, 2014 Accepted: August 28, 2014 Online Published: October 15, 2014 \\ doi:10.5539/jas.v6n11p74 \\ URL: http://dx.doi.org/10.5539/jas.v6n11p74
}

\begin{abstract}
The present article “Azerbaijan's Current and Potential Comparative Advantage”, which has been prepared as a contribution to the National Employment Strategy, provides an analysis of the sectors and industries in which Azerbaijan is either currently competitive or there is a potential to become competitive in the future. This study proves the existence of the competitive, non-oil sectors in Azerbaijan and there are justifiable reasons to suppose that new and competitive industries can develop in the future. Along with the analyses of the current competitive sectors in Azerbaijan, this report recommends to undertake detailed and comprehensive analysis of those sectors which are proved to be currently competitive and to identify the key obstacles hindering their development. These further investigations should also provide a basis for linking comparative advantage with labor markets to create the conditions for competitive industries that generate more employment in the sectors outside oil and gas.
\end{abstract}

Keywords: Azerbaijan economy, oil sector, non-oil sectors, labor markets, comparative advantage

\section{JEL classifications: E24, F11, F14, F16}

\section{Introduction}

Azerbaijan gained its independence from the Soviet Union in 1991, but the country continues to face considerable problems in making the transition from a command to a market economy, including the loss of its traditional markets, the need to diversify its economy, excessive bureaucratic regulation, and the slow pace of structural reforms. Azerbaijan is an industrial-agricultural republic. The diversified economy of Azerbaijan is based on the use of rich and various mineral reserves. Besides oil and gas, the reserves of iron ore, zinc ore, molybdenum ore, alunite, rock salt, boring waters containing iodine and bromine, gypsum, limestone, bitumen, clay, and marble are used in industrial exploitation, including, hydroelectric power resources.

The agriculture of the Republic is specialized in the cultivation of vegetables, fruits, cotton, tobacco, subtropical cultures, silkworm and sheep breeding. Accordingly, special place in the industrial structure of the country is shared by the fields busy with the primary processing of the agricultural raw material. Azerbaijan possesses considerable labor manpower reserves, as the result of natural accretion of the population. An extensive transport network supplies the developing economic relations of Azerbaijan with foreign countries. Azerbaijan is distinguished as an area of oil extraction and refining, chemical, electromechanical industries, oil engineering and machine building, ferrous and nonferrous metallurgy industries, production of building materials, light and food industries. The main sections of the Republic's economy are the branches of heavy industry and industry on the whole.

Azerbaijan's oil sector generates 42.0 percent of the gross domestic product but only 0.9 percent of all jobs. That's why encouraging new businesses in the non-oil sector to spur economic development is one of the biggest challenges of the Government of Azerbaijan. The Government of Azerbaijan with the support of international organizations (UNDP, ILO) developed an employment strategy for the solving of these problems. The creation of new jobs and the upgrading of existing jobs have been a key focus of the Government of Azerbaijan.

An employment strategy must be developed on the base of results of scientifically justified researches and analyses. It is of great importance to define the sectors (products) and sub-sectors of the economy which are competitive in world markets and which have the potential comparative advantage for the creation of new jobs. 
And today, the question of which Azerbaijani products have a comparative advantage is becoming increasingly relevant and important as the world markets become more and more competitive.

This study provides an analysis of the sectors and industries in which Azerbaijan is either currently competitive or for which there is initial evidence that it might have the potential to become competitive in the future. There are four main areas/objectives that this analysis is intended to address. Brief description of these areas follows:

\subsection{Competition and Trade Policy}

In discussion with respect to the employment strategy, the need for Azerbaijan to develop a solid base of non-oil sectors which are internationally competitive was widely recognized. To do this, it is necessary to create an environment of competition by removing barriers to competition both between Azerbaijani firms and with respect to foreign competitors. However, the Government of Azerbaijan, like many governments in other countries are likely to have concerns with respect to opening national markets to domestic and foreign competition.

In any country, it is easy to identify those sectors of the economy that are likely to be adversely affected by policy liberalization. That is, it is usually easy to see where firm closures and job losses are likely to occur in those industries which are hopelessly uncompetitive. These are obvious to any government because these industries actually exist.

However, what is much harder for governments to see is that liberalization does not just destroy jobs in existing, uncompetitive industries, but also creates new jobs in competitive new or expanding industries. Overall, Azerbaijan's economy would be better off if existing uncompetitive sectors could be replaced with competitive new sectors or the expansion of existing competitive ones. The problem for governments is that the loss of jobs in uncompetitive sectors is easy to see, but the creation of new jobs by sectors which either do not exist at present or exist on a small scale is much harder to conceive.

The first objective of this study is, therefore, to assess whether there is a realistic possibility of competitive sectors developing in Azerbaijan. It does not and cannot provide any firm evidence or guarantee that specific sectors will develop. What it is intended to do is to reassure the government that there is in general a realistic prospect that the effects of liberalizing competition and trade will include long term increases in jobs in new or expanded industries as well as short term losses in jobs in uncompetitive ones.

\subsection{Removing Constraints to Business}

The Employment Strategy and earlier studies of business in Azerbaijan have provided much useful insight concerning the obstacles and constraints affecting existing business in Azerbaijan. However, this analysis needs to be extended and developed further. In particular, the question needs to be asked: "What has prevented new competitive industries developing in Azerbaijan and what has prevented existing sectors which are currently competitive from operating on a larger scale?" To do this requires some broad idea of where Azerbaijan's current and potential advantages lie. This study is intended to provide this basis for further identifying the key constraints involved and in developing policy responses to remove them.

\subsection{Promoting Inward Foreign Direct Investment}

Given the small size of Azerbaijan's economy, many possible foreign investors are only likely to be interested in Azerbaijan if it offers the potential to produce competitively for export to other markets. However, for such projects Azerbaijan is just one of many locations that investors could choose. To select their preferred location investors must therefore choose between many locations, many of which they will have very limited information about.

To attract such investors, investment promotion agencies in many countries provide a broad list of sectors which potential investors might consider further. This does not provide investors with any firm or certain "winners", but simply helps investors to identify which sectors in Azerbaijan might be worth undertaking a much more detailed investigation of feasible projects. A further objective of this study is to provide such a "first screening" for the purposes of investment promotion.

\subsection{Removing Interventionism}

This study is intended to produce a broad and general assessment of what the structure of production might be in Azerbaijan under free competition and trade. It is not intended as and can never serve as a basis for picking winners. The establishment of new state enterprises in any sectors identified as competitive or potentially competitive would be most unlikely to succeed. Using public funds rather than the investors' own funds removes key incentives for entrepreneurship and efficiency with the results that such firms would be much less likely to 
be competitive. Creating publicly owned firms also creates incentives for the government to protect them against both domestic and foreign competitions precisely the opposite of what this study seeks to show is needed to develop competitive industry.

Likewise, this study could be misinterpreted as providing the basis not for direct government ownership of business, but for a policy of steering or interventionism. For the same reasons - that protecting, subsidizing or otherwise distorting market incentive inhibits rather than encourages competitiveness - the intention of this study is the opposite. The study seeks to demonstrate that Azerbaijan has less to fear and more to gain from liberalized markets than is currently supposed.

The second section of this paper provides an overview of the relevant economic theories of international trade, including the theory of comparative advantage. The methodology and data are explained in Section 3, while Section 4 presents and discusses the results, including the Balassa RCA index, net export ratios, and Finger and Kreinin index. Section 5 concludes the paper.

\section{Overview of Economic Theories of International Trade}

\subsection{International Trade and Comparative Advantage}

The theory of comparative advantage is one of the oldest economic theories of trade, dating from David Ricardo (1817). To this date, it remains the dominant explanation of why any country would specialize in exporting certain categories of goods and services and in importing others. It can be seen as a cost-based explanation of international trade.

The earliest theory of international trade and absolute advantage was put forward by Adam Smith (1766). Smith argued that countries will tend to export those goods or services which they are capable of producing more cheaply than their trading partners and tend to import those which they are only capable of producing more expensively. Ricardo's first contribution (1817) was to show that such trade does not depend so much on differences between countries in the prices of individual goods and services, but on differences in the prices of one good or service relative to another. Accordingly Ricardo's theory of comparative advantage predicts that countries export goods which they are capable of producing relatively cheaply compared to their trading partners and import goods which they are capable of producing relatively more expensive.

It is easy to see how a country, which is capable of producing a good or service more cheaply than other countries, would export it. Extending this from absolute to relative prices is more complex, but still comparatively straightforward. Unfortunately, interpreting comparative advantage is more complex. In this context, being capable of producing a good more cheaply does not mean that we can simply check the current relative prices of different goods or services and expect them to match up with observed trade flows. This is because international trade itself changes the prices of goods and services. Many goods and services are traded at world prices, which bear no necessary relationship to domestic cost conditions. Since it is difficult to think of many cases where individual countries have ever been so isolated, it is impossible to ever observe such prices.

Since we cannot directly observe comparative advantage (the difference between countries in relative prices when they are wholly isolated from international trade), it is necessary to extend the comparative advantage theory to establish what underlying forces would create it. The starting point for this is to ask what can create cost differences in the production of goods and services between countries. Essentially, there are two possibilities why costs might differ between countries. Firstly, one country might simply use the same resources more efficiently than another. Secondly, one country might be able to obtain key inputs more cheaply than another.

Ricardo's (1817) own explanation was one of the former sets of explanations. According to Ricardo's theory, differences in relative costs were caused by differences in the (relative) productivity of labor between countries. To this date, Ricardian comparative advantage is still seen as an important explanation of international trade, although modern writers are much more likely to cite technological differences as the primary cause of international differences in productivity.

Economic theories making use of the second type of explanation (differences in the costs of factor inputs) first arose with Heckscher (1919) and Ohlin (1933). The Heckscher-Ohlin (H-O) model of international trade sees comparative advantage as being determined by international differences in the supplies of factors of production. In its simplest form, the model has two factors of production capital and labor. Suppose one country, say the USA, has more capital per worker than a second country, say India. This would imply that the price of capital relative to labor would be cheaper in the US than in India. Assuming that there are no significant differences in technology between the two, this would also imply that the cost of producing goods or services using capital intensiveness relative to those using labor intensively would be lower in the US than in India. In other words, a 
comparative advantage would exist.

A common misconception with the H-O model is that it deals with only capital and labor. In fact, it can be shown to apply with many factors of production. With multiple factors of production its core prediction is quite simple. Countries will tend to have a comparative advantage and, therefore, to export goods or services which make intensive use of those factors of production in which they are comparatively rich. Conversely, they will tend to import goods or services which make intensive use of factors of production in which they are comparatively poor Much of recent empirical research on the H-O model emphasizes the importance of skills and education in the labor force as a key determinant of comparative advantage and trade (Webster, 1993; Webster \& Hardwick, 2005).

In the light of successful integration of the Ricardian and $\mathrm{H}-\mathrm{O}$ views on the comparative advantage by Davies (1995), a single, combined view of comparative advantage was used in this study. This unified model predicts that comparative advantage is simultaneously determined by both international differences in technology and by international differences in the available supplies of factor inputs.

There are a number of theories which explain why countries might simultaneously export and import the same good or service. The majority of these require some form of product differentiation either in terms of quality or simply in terms of different varieties of the same good. Taking, firstly, differences in quality, Falvey (1981) sets out a model which essentially predicts that countries may have a comparative advantage in one quality of a good or service. For example, Italy might export high quality designer clothing and import low quality clothing, with the underlying reason for Italy's comparative advantage in high quality clothing arising from Italy's superior design or designers.

A second category of models, most commonly associated with Krugman (1979), considers the case where goods or services do not differ with respect to quality but where one variable is simply made different from another. In these models, international trade arises for two key reasons. Firstly, individual consumer has a taste for variety such that they prefer to consume different varieties of the same good or service. Secondly, economies of scale mean that the domestic market can only produce a fixed number of varieties. Suppose, for example, there are two countries, each of which produces 10 varieties of the same good or service. By engaging in international trade, both countries could now increase the number of varieties to 20 . However, it is also likely that both countries would produce fewer varieties say, each now produces only 8 . Both countries could now consume 16 varieties, substantially more than without trade, but the reduction in the number of varieties produced means that economies of scale can be best exploited. Under these circumstances trade occurs because consumers not only obtain greater variety, but also obtain each variety at lower cost.

Another closely related, the theory is that put forward by Lancaster (1980). In this model, consumers do not have an individual taste for variety and buy only a single variety. However, consumers differ from each other in terms of the variety that they would most like to buy. Since consumers differ from each other according to their preferred (ideal) variety, this means that there is a taste for variety in aggregate. From this point the model is essentially similar to the case of an individual taste for variety. That is, international trade enables consumers to obtain a variety nearer to their ideal and, by reducing, the number of varieties produced, to obtain their preferred variety at lower cost.

The final category of the model associated with Brander and Krugman (1983) assumes that products are not differentiated at all. Instead, they assume that the market for a particular good is characterized by imperfect competition. In the simplest case, take two countries, each of which has a single national monopolist, protected by barriers to trade. Now remove these trade barriers. The two national monopolists now, in effect, constitute an international duopoly. Under these circumstances the international rivalry between the two firms will ensure that both have little choice other than to supply each other's markets. In this case, international trade (intraindustry) arises as a direct result of rivalry between firms in monopolized sectors of the economy.

\subsection{Summary and Implications of Trade Theory}

Based on the preceding discussion, we can establish a number of comparatively simple predictions of the economic theories of trade with respect to international trade in goods and services. These are

Prediction 1: countries will tend to export and import the same goods to each other where national markets are highly monopolized.

Prediction 2: countries will tend to export and import the same good (service) to each other where product differentiation is important.

Prediction 3: countries will tend to export and import the same good (service) to each other where significant 
differences in product quality exist.

Prediction 4: countries will tend to, on balance, export a specific good where they have a technological or productivity advantage.

Prediction 5: countries will tend to, on balance, export a specific good which uses intensively factor inputs in which they are comparatively rich and to import a good which makes intensive use of factor inputs in which they are comparatively poor. From the point of view of trade it would seem that all of these theoretical predictions have potential relevance.

\section{Methodology and Data}

\subsection{Methodology of Revealed and Potential Comparative Advantages Analysis}

Comparative advantage is, as previously discussed, notoriously difficult to measure. Officially, a comparative advantage is a difference between countries in the relative prices that would prevail if these countries were isolated from trade. Since we cannot observe this isolation, comparative advantage cannot be directly measured. It is, however, possible to observe the underlying conditions which give rise to comparative advantage. That is, we could attempt to measure both differences in technology or productivity and differences in the supplies of factor inputs. However, to do so would be a colossal task.

In consequence, the most common approach is to invoke Balassa's (1965) principle of revealed comparative advantage. This argues that, since trade is generated by underlying comparative advantage, we can use data on exports and imports to infer this underlying pattern of advantage. This principle has given rise to a number of indicators of revealed comparative advantage (RCA). For the purposes of this paper we utilize two of these measures.

The first of these measures is the index proposed by Balassa (1965) himself. The Balassa index (Bij) is given as:

$$
\mathbf{B}_{\mathrm{ij}}=\mathbf{X}_{\mathrm{ij}} / \mathbf{X}_{\mathrm{iw}}
$$

Where $\mathbf{X}_{\mathrm{ij}}$ is the share of service (or good) $\mathbf{i}$ in country $\mathbf{j}$ 's total exports and $\mathbf{X}_{\mathrm{iw}}$ is the share of good in total world exports.

The Balassa index simply takes the ratio of the share of good $\mathbf{i}$ (say, crude oil) in country $\mathbf{j}$ 's total exports to the share of the same good in total world exports. Thus, if crude oil is more important in country j's exports than they are in total world exports, then the measure suggests that country $\mathbf{j}$ has a revealed comparative advantage in the good concerned. Accordingly, values of the Balassa index greater than 1 are taken to "reveal" a comparative advantage whilst values less than 1 are taken to reveal a disadvantage.

The second of these measures of RCA is the net export ratio $\left(\mathbf{N E R}_{\mathrm{ij}}\right)$. The next export ratio is defined as:

$$
\operatorname{RCANER}_{\mathrm{ij}}=\left(\mathbf{X}_{\mathrm{ij}}-\mathbf{M}_{\mathrm{ij}}\right) /\left(\mathbf{X}_{\mathrm{ij}}+\mathbf{M}_{\mathrm{ij}}\right)
$$

Where $\mathbf{X}_{\mathrm{ij}}$ are the exports of good (or service) $\mathbf{i}$ by country $\mathbf{j}$ and $\mathbf{M}_{\mathrm{ij}}$ the imports of good $\mathbf{i}$ into country $\mathbf{j}$.

The rationale behind the index is that countries are "revealed" as having a comparative advantage in a particular good or service if they export more of it than they import. However, to simply consider net exports (exports less imports) might be misleading where, for example, we compare a large and a small country. For this reason, net exports are divided by total trade (exports plus imports). Net export ratios have a minimum value of 1 (the country only imports the good concerned) and a maximum value of +1 (the country only exports the good). Negative values are taken to "reveal" a disadvantage and positive values an advantage.

Ballance, Forstner and Murray (1986) discussed the possible interpretations of RCA indices. Firstly, RCA indices provide dichotomous measures of revealed advantage. That is, we can use the different indices to establish whether any given country has a comparative advantage or disadvantage in a particular good. Secondly, it is possible to use RCA indices to provide rankings. For example, we could take single good and rank countries according to their revealed advantage or we could take a single country and rank goods and services according to their revealed advantage. However, RCA indices cannot be interpreted as cardinal measures. The values of RCA indices themselves have no meaning except in relation to other industries or countries or as a dichotomous measure.

Finally, RCA indices have one major flaw. The principle of revealed comparative advantage presumes that observed trade flows are generated by underlying comparative advantages and disadvantages. It is this which allows us to use observed trade data to infer the underlying pattern of advantage. However, observed trade flows are not just created by underlying economic forces, but are often significantly affected by government policies with respect to international trade. This problem is potentially more serious for trade in services than for trade in 
goods. Liberalization of trade in goods is sufficiently advanced that it is at least possible to claim that trade policies are unlikely to have materially affected observed exports and imports. For services, where liberalization is less well advanced and where protection against import competition has traditionally been through a series of measures whose effects are unclear, this is a much less credible claim.

In consequence, RCA indices remain reliable measures of whether any country has an advantage or not in a specific good (i.e. as a dichotomous measure). As mentioned above Balassa index and net export ratio help to define goods (or services) which have comparative advantage currently. It is also possible to define potential comparative advantages. First thing here is to know which country is similar to the country (let's say to Azerbaijan). From the viewpoint of comparative advantage, similarity of economies is treated as a main indicator Similarities in technologies, productivity, production and other factors are considered as the main ones for comparison. This creates a hypothesis about the possibility of a good exported in similar country to be exported by the country.

Exports similarity is measured by Finger and Kreinin index:

$$
\mathrm{XS}=\sum_{\mathrm{i}=1}^{\mathrm{n}} \min (\mathrm{Xia}, \mathrm{Xib})
$$

Where Xia - share of good in the export of country A, Xib - share of good in the export of country $\mathbf{B}$, and $\mathbf{i}=$ 1 ... n (for all products $n$ ).

Country's export similarity to total world export can be taken as a basis and export similarity to other countries (indicator) should be compared to it. At least, country's export similarities indicator, to more than 30 countries should be calculated (we calculated export similarity of Azerbaijan with 84 countries). The question here is what products are exported by these countries that the country (for example, Azerbaijan) can export. For this reason, we measure Balassa net export for these countries. This shows products of these countries which have comparative advantage. From this list we can find products which have comparative advantages and use it as a hypothesis. As a result, we get the list of potential products for more comprehensive analysis.

\subsection{Data}

All data used in this paper were taken from the World Integrated Trade Solution (the World Bank) database and PCTAC trade statistics (World Trade Organization) database. This database provides information on the exports and imports of different categories of goods for a sample of 183 countries. Database of the last 3 years (2007-2009) were used for the calculations. Using these databases, we conducted an analysis based on standard theories and empirical techniques for international trade.

\section{Analysis of Results and Discussion}

In this section, we present three sets of analysis. Firstly, we present an analysis of exports of Azerbaijan using the Balassa index of revealed comparative advantage (RCA). Secondly, we present a similar analysis using the net export ratio measure of RCA. Finally, we present exports similarity of Azerbaijan with other countries using the Finger and Kreinin index.

\subsection{Balassa Revealed Comparative Advantage Indices}

In Table 1, we present Balassa RCA indices in 4 digit production code (SITC 3 Revision) for Azerbaijan Republic. These are annual values for the years 2007 to 2009. Formally the Balassa indices (see section 4) are defined to be the ratio of the share of the good in the country's total exports to the share of the same good in total world exports.

Computation of Balassa RCA indices for Azerbaijan shows followings:

Agricultural products (processed and semi processed agricultural products included):

Being partly agricultural country Azerbaijan has revealed comparative advantage in tobacco, apple, nuts, tea, vegetables, oilseeds, raw cotton, and pharmaceutical plants growing. Stripped tobacco and nuts have bigger revealed comparative advantage rate within agricultural products.

Silk worm cocoons, animal skins (raw) can be added to the list of competitive agriculture goods also. Development of agro-processing industry in recent years in Azerbaijan affected its position in world markets. Fruit juices, cigarettes, manufactured tobacco, animal skins, cotton linters, carded/combed cotton (332.38, the biggest Balassa RCA indices for Azerbaijan), cotton seed oil, safflower oil became competitive in world markets. For example, Balassa RCA indices for fruit juices, cigarettes was less than 1.00 in year 2007, but in the year 2009 it reached more than 2.00 .

Oil and oil products: As it was expected oil industry has the biggest revealed comparative advantage (average) in 
main export goods: crude oil 22.37; Kerosene/medium oils 129.83; Motor spirit/light oils 20.05; Gas oils -95.66; Fuel oils - 29.35. The major problem here is that crude oil accounts for $60-80$ per cent of total export. In other words, share of finished products is not too big, even though they have bigger Balassa RCA indices than crude oil.

Table 1. Balassa revealed comparative advantage indices

\begin{tabular}{|c|c|c|c|c|c|}
\hline Product Code & Description & 2007 & 2008 & 2009 & 2007-09 (Average) \\
\hline 2634 & Cotton, carded/combed & 539.32 & 207.40 & 250.43 & 332.38 \\
\hline 3342 & Kerosene/medium oils & 35.57 & 22.97 & 330.97 & 129.83 \\
\hline 3343 & Gas oils & 39.74 & 34.58 & 212.66 & 95.66 \\
\hline 4212 & Cotton seed oil & 46.30 & 45.25 & 69.93 & 53.83 \\
\hline 3344 & Fuel oils, net & 0.02 & 5.59 & 82.45 & 29.35 \\
\hline 3330 & Petrol. /bitum. Oil, crude & 26.62 & 17.97 & 22.53 & 22.37 \\
\hline 3341 & Motor spirit/light oils & 5.63 & 4.22 & 50.31 & 20.05 \\
\hline 1211 & Tobacco, not stripped & 16.82 & 16.85 & 17.15 & 16.94 \\
\hline 577 & Nuts edible fresh/dried & 15.11 & 6.09 & 9.79 & 10.45 \\
\hline 2852 & Aluminum oxide & 12.70 & 4.96 & 11.55 & 9.73 \\
\hline 4229 & Fix veg fat, not soft & 17.64 & 4.22 & 5.62 & 9.16 \\
\hline 8986 & Recorded magnetic tapes & 7.04 & 12.96 & 2.29 & 7.43 \\
\hline 548 & Veg prod, fresh/dried & 6.04 & 5.71 & 5.96 & 5.77 \\
\hline 6581 & Textile sacks/bags & 5.90 & 3.78 & 6.43 & 5.37 \\
\hline 2114 & Goat/kid skins, raw & 0.22 & 7.28 & 7.49 & 5.00 \\
\hline 741 & Tea & 4.31 & 3.47 & 6.37 & 4.72 \\
\hline 2632 & Cotton linters & 9.13 & 2.52 & 1.29 & 4.31 \\
\hline 2924 & Pharmaceutical plants & 3.75 & 3.85 & 4.82 & 4.14 \\
\hline 3510 & Electrical energy & 6.77 & 1.02 & 4.61 & 4.13 \\
\hline 2631 & Raw cotton, excl linters & 2.91 & 0.22 & 7.48 & 3.54 \\
\hline 2116 & Sheep skin w/wool & 5.19 & 1.76 & 1.93 & 2.96 \\
\hline 355 & Fish meal fit for food & 2.33 & 2.23 & 2.76 & 2.77 \\
\hline 5711 & Polyethylene & 3.24 & 0.89 & 4.12 & 2.75 \\
\hline 2614 & Silk worm cocoons/waste & 3.34 & 2.83 & 1.95 & 2.70 \\
\hline 7239 & Earth moving mach parts & 2.02 & 2.60 & 2.13 & 2.25 \\
\hline 5121 & Acyclic monohyd alcohols & 2.32 & 1.14 & 3.15 & 2.20 \\
\hline 1223 & Manufactured tobacco & 1.61 & 3.08 & 1.81 & 2.17 \\
\hline 3354 & Petrol. bitumen/coke/etc & 0.61 & 1.55 & 3.88 & 2.01 \\
\hline 3345 & Lubs(high petr cont) etc & 2.35 & 0.38 & 3.25 & 2.00 \\
\hline
\end{tabular}

Chemical and petrochemical industry: Other major sector of the national economy has revealed comparative advantage in polyethylene (2.75), plastics production and ethylene production. Mining industry: Except for crude oil, Azerbaijan has revealed comparative advantage in alumina (aluminium oxide) mining. Non-oil sector: The sector is represented by construction/mining machinery, earth moving machinery parts, pumps, liquid elevators, special-use vehicles, gas/liquid/electricity meters, tugs and pusher craft, navigation/survey apparatus, textile sacks, bags, recorded magnetic tapes. 


\subsection{Net Export Ratios}

Table 2 presents net export ratio measures of RCA. As with the Balassa indices these are presented for total export-import of goods. The objectives of the analysis are identical to those described in the preceding section. However, repetition of the analysis using net export ratios is of importance because of the differences between the Balassa and net export ratio measures. Balassa indices essentially use export performance as an indicator of comparative advantage, whereas net export ratios use both import and export data. For our findings to be robust it is necessary that both measures provide broadly similar conclusions.

Examination of the results in total immediately reveals that the use of net export ratios (NERs) makes only a limited difference to the results. With the exception of some non-oil products (for which the reason may be import of analogical equipment by new enterprises and Trans National Corporations) the products which have a comparative advantage, according to the Balassa index, have a comparative advantage according to the NER measure, too. The case of non-oil products, especially equipment, can be explained from another point of view also. Balassa index shows that some Azeri non-oil products (equipments) have a comparative advantage in world markets. So, maybe instead of importing these products from other countries, it is better to support the development of analogical products locally. Some products which are not included in Table 1 but are in Table 2 have a small share in total export of the country and generally agricultural products. (Exceptions are gas turbines, polyacetals/polyethers, paper making machines and some other products).

Fish meal fit for food was totally imported in 2007, but Azerbaijan started to export this good in 2009. That's why we have 0.00 in the average NER. But it does not mean that Azerbaijan has no comparative advantage in the export of fish meal fit for food. Change from import to export of the product can be considered as a good tendency due to establishment of production of the same product in the country. And Balassa index shows that Azerbaijan has comparative advantage in this product. But generally, in this paper, calculations according to the Balassa index and according to net export ratios give almost similar results.

\subsection{Potential Comparative Advantage}

In this section Table 3 presents an export similarity of Azerbaijan with 84 countries. This is intended to achieve one main objective. As discussed in section 3, it is possible to create a hypothesis about the possibility of a good exported in similar country to be exported from Azerbaijan. If we know which country's export structure is similar to Azerbaijan's export structure. The main points here are similarities in technologies, productivity, and production. Unfortunately, data for some countries was not fully provided. Our results must, therefore, be regarded as indicative rather than conclusive. We took Azerbaijan's export similarity to total world exports as basis and compared indicator of export similarity of Azerbaijan to other countries to it.

Table 2. Net export ratios

\begin{tabular}{cccccc}
\hline Product code & Description & $\mathbf{2 0 0 7}$ & $\mathbf{2 0 0 8}$ & $\mathbf{2 0 0 9}$ & $\mathbf{2 0 0 7 - 0 9}$ (Average) \\
\hline $\mathbf{3 5 1}$ & Fish,dried/salted/brine & -0.74 & 0.75 & 0.80 & 0.27 \\
$\mathbf{3 7 1}$ & Fish, prepared/preserved & 0.63 & 0.17 & 0.05 & 0.28 \\
$\mathbf{5 4 4}$ & Tomatoes fresh/chilled & -0.11 & -0.05 & 0.92 & 0.26 \\
$\mathbf{5 4 8}$ & Veg prod nes,fresh/dried & 0.98 & 1.00 & 0.98 & 0.99 \\
$\mathbf{5 6 4}$ & Fruit/veg flour/meal nes & -1.00 & 1.00 & 0.42 & 0.14 \\
$\mathbf{5 7 4}$ & Apples fresh & 0.33 & 0.45 & 0.69 & 0.49 \\
$\mathbf{5 7 7}$ & Nuts edible fresh/dried & 0.98 & 0.94 & 0.99 & 0.97 \\
$\mathbf{5 7 9}$ & Fruit fresh/dried nes & 0.64 & 0.66 & 0.87 & 0.72 \\
$\mathbf{5 8 1}$ & Fruit jams/jellies/etc & 0.44 & 0.00 & -0.19 & 0.08 \\
$\mathbf{5 9 9}$ & Fruit juices nes/mixture & -0.11 & 0.26 & 0.46 & 0.20 \\
$\mathbf{6 2 1}$ & Fruit preserved by sugar & 0.97 & 1.00 & 0.61 & 0.86 \\
$\mathbf{8 1 1}$ & Hay/fodder, green/dry & -0.18 & 1.00 & -0.41 & 0.14 \\
$\mathbf{8 1 4}$ & Meat/fish meal fodder & 1.00 & 1.00 & 1.00 & 1.00 \\
$\mathbf{1 1 2 1}$ & Wine of fresh grapes & 0.80 & 0.81 & -0.76 & 0.28 \\
$\mathbf{1 1 2 4}$ & Distilled alcoholic bev & 0.71 & 0.89 & 0.27 & 0.62 \\
$\mathbf{1 2 1 1}$ & Tobacco, not stripped & 0.98 & 0.69 & 0.23 & 0.64 \\
& & & & & \\
\hline
\end{tabular}




\begin{tabular}{|c|c|c|c|c|c|}
\hline 1222 & Cigarettes (tobacco) & -0.17 & 0.41 & 0.20 & 0.15 \\
\hline 2111 & Bovine/equine hide raw & 1.00 & 1.00 & 0.84 & 0.95 \\
\hline 2112 & Bovine hides, whole, raw & 0.96 & 1.00 & 0.97 & 0.98 \\
\hline 2114 & Goat/kid skins, raw & 1.00 & 1.00 & 1.00 & 1.00 \\
\hline 2116 & Sheep skin common w/wool & 0.98 & 0.88 & 0.98 & 0.95 \\
\hline 2117 & Sheep skin without wool & 1.00 & 1.00 & 1.00 & 1.00 \\
\hline 4222 & Soya beans & 1.00 & & -1.00 & 0.00 \\
\hline 2237 & Oil seeds/oil fruits nes & -1.00 & 0.99 & 0.99 & 0.33 \\
\hline 2321 & Rubber synth from oil & -0.40 & -0.19 & 0.63 & 0.01 \\
\hline 2475 & Hardwood,rough,untreated & 1.00 & 1.00 & -1.00 & 0.33 \\
\hline 2511 & Paper/board waste/scrap & 0.99 & 1.00 & 1.00 & 1.00 \\
\hline 2614 & Silk worm cocoons/waste & 1.00 & 1.00 & 1.00 & 1.00 \\
\hline 2631 & Raw cotton,excl linters & 1.00 & 1.00 & 1.00 & 1.00 \\
\hline 2633 & Cotton waste & 1.00 & 1.00 & 1.00 & 1.00 \\
\hline 2634 & Cotton, carded/combed & 1.00 & 1.00 & 1.00 & 1.00 \\
\hline 2682 & Woolnes, uncombed & 1.00 & -0.32 & 1.00 & 0.56 \\
\hline 2823 & Ferrous waste/scrap nes & 1.00 & 0.94 & -1.00 & 0.31 \\
\hline 2852 & Alumina(aluminium oxide) & 1.00 & 1.00 & 1.00 & 1.00 \\
\hline 2882 & Non-fer metal waste nes & 0.99 & 1.00 & -1.00 & 0.33 \\
\hline 2924 & Pharmaceutical plants & 1.00 & 1.00 & 1.00 & 1.00 \\
\hline 3330 & Petrol./bitum. oil,crude & 1.00 & 1.00 & 1.00 & 1.00 \\
\hline 3341 & Motor spirit/light oils & 1.00 & 1.00 & 1.00 & 0.99 \\
\hline 3342 & Kerosene/medium oils & 1.00 & 0.99 & 0.96 & 0.99 \\
\hline 3343 & Gas oils & 0.95 & 0.91 & 0.97 & 0.94 \\
\hline 3344 & Fuel oils,nes & -0.95 & 1.00 & 1.00 & 0.35 \\
\hline 3351 & Petroleum jelly/waxes & -1.00 & 0.98 & 0.82 & 0.27 \\
\hline 3354 & Petrol. bitumen/coke/etc & 0.94 & 0.98 & 0.97 & 0.97 \\
\hline 4111 & Fish/marine mamm.oil/fat & 1.00 & 1.00 & 1.00 & 1.00 \\
\hline 4212 & Cotton seed oil & 0.79 & 0.67 & 0.98 & 0.81 \\
\hline 4214 & Olive oil & -0.32 & 0.17 & 0.42 & 0.09 \\
\hline 4229 & Fix veg fatness not soft & 0.35 & 0.61 & -0.52 & 0.14 \\
\hline 4311 & Animal/veg oil modified & 0.67 & 0.41 & 1.00 & 0.69 \\
\hline 5111 & Acyclic hydrocarbons & 0.52 & 0.81 & 0.99 & 0.77 \\
\hline 5113 & Halogenated hc derivs & 0.89 & 0.78 & 0.79 & 0.82 \\
\hline 5121 & Acyclic monohyd alcohols & 0.34 & 0.30 & 0.52 & 0.39 \\
\hline 5161 & Ethers/peroxides/derivs & 0.92 & 0.81 & 0.75 & 0.83 \\
\hline 5711 & Polyethylene & 0.95 & 0.94 & 0.88 & 0.92 \\
\hline 5741 & Polyacetals/polyethers & 0.62 & 0.80 & 0.75 & 0.72 \\
\hline 5759 & Plastics & 0.65 & 0.23 & 0.83 & 0.57 \\
\hline 6581 & Textile sacks/bags & 0.60 & 0.42 & 0.79 & 0.60 \\
\hline 6593 & Hand woven rugs & 0.99 & 1.00 & 0.88 & 0.96 \\
\hline 6595 & Carpets, woven & -0.04 & 0.01 & 0.59 & 0.19 \\
\hline 6821 & Copper refined/unrefined & 0.98 & 1.00 & -1.00 & 0.33 \\
\hline 7148 & Gas turbines & 0.91 & 0.43 & 0.08 & 0.47 \\
\hline 7251 & Pulp/Paper making machines & 0.91 & -0.81 & 0.75 & 0.28 \\
\hline 7465 & Cyl roller bearings & -0.84 & 0.69 & 0.31 & 0.05 \\
\hline 8986 & Recorded magnetic tapes & 0.61 & 0.81 & 0.17 & 0.53 \\
\hline
\end{tabular}


As is seen from Table 3, there are 24 countries above medium (world level) and most of them are oil exporter countries. As we mentioned above, crude oil accounts for about 60-80 per cent of total exports of Azerbaijan (This figure is about 90 per cent of oil products) and finally it influences summary of minimums during the calculation of export similarities with oil exporter countries drastically. For example, in year 2000 crude oil accounts for 48.9 per cent of total export of Norway, its share for Azerbaijan is 56.4 per cent. So, 0.489 out of total export similarity value for Azerbaijan and Norway comes from crude oil in 2000. The same can be said about Iran, Saudi Arabia, Venezuela, Nigeria, Kazakhstan, Algeria, Qatar, Ecuador, Russian Federation, and Columbia.

We think there is a need for more detailed analyses. It is necessary to calculate all Balassa indices for non-oil sector (excluding oil sector from the export of Azerbaijan and other countries, also from total world export) by using the methodology of this paper.

There are some other countries with which Azerbaijan has export similarities, too. These countries also have a big export of oil products, but they don't export crude oil like above mentioned countries, they export processed oil products such as motor spirit/light oils, kerosene/medium oils, gas oils, lubricants (high petrol concentration) etc. And it makes sense to investigate the export structure of these countries and try to find products which should be exported by Azerbaijan.

Table 4 includes a more detailed list of the products in which similar countries currently have a revealed advantage but Azerbaijan does not. No doubt, with the large number of similar countries identified ( 24 countries); it is difficult to produce a table including products from all similar countries. To reduce results to more manageable proportions we suggested using data from the countries at the top of the Table 3 and from some developed countries like the United Kingdom, Canada, and Australia which are also above the median (basis). The rank column of the resulting table provides number of countries which currently have a revealed advantage in certain product according to 2007-2009 average. We analyzed and presented list of products in which four or more similar countries have a revealed advantage.

Table 3. Export similarity of Azerbaijan with other countries

\begin{tabular}{|c|c|c|c|c|c|}
\hline Country & ESI & Rank & Country & ESI & Rank \\
\hline Iran & 0.6883 & 1 & Poland & 0.0570 & 42 \\
\hline Saudi Arabia & 0.6726 & 2 & Morocco & 0.0565 & 43 \\
\hline Venezuela & 0.6035 & 3 & Peru & 0.0556 & 44 \\
\hline Nigeria & 0.5657 & 4 & Italy & 0.0553 & 45 \\
\hline Kazakhstan & 0.5334 & 5 & Romania & 0.0542 & 46 \\
\hline Norway & 0.5224 & 6 & Germany & 0.0542 & 47 \\
\hline Algeria & 0.5004 & 7 & Thailand & 0.0523 & 48 \\
\hline Qatar & 0.4744 & 8 & Belarus & 0.0521 & 49 \\
\hline Ecuador & 0.4371 & 9 & Czech Republic & 0.0508 & 50 \\
\hline Colombia & 0.2924 & 10 & Yugoslavia & 0.0506 & 51 \\
\hline Russian Federation & 0.2917 & 11 & Bulgaria & 0.0501 & 52 \\
\hline Trinidad and Tobago & 0.2171 & 12 & New Zealand & 0.0493 & 53 \\
\hline Argentina & 0.1831 & 13 & Bolivia & 0.0490 & 54 \\
\hline Lithuania & 0.1769 & 14 & Kyrgyzstan & 0.0480 & 55 \\
\hline Cote d'Ivoire & 0.1722 & 15 & Syrian Arab Republic & 0.0475 & 56 \\
\hline Egypt & 0.1520 & 16 & Austria & 0.0473 & 57 \\
\hline Bahrain & 0.1477 & 17 & China & 0.0470 & 58 \\
\hline Indonesia & 0.1460 & 18 & Portugal & 0.0461 & 59 \\
\hline Greece & 0.1310 & 19 & India & 0.0448 & 60 \\
\hline Australia & 0.1199 & 20 & El Salvador & 0.0446 & 61 \\
\hline Mexico & 0.1142 & 21 & Slovak Republic & 0.0430 & 62 \\
\hline Turkmenistan & 0.1142 & 22 & Slovenia & 0.0419 & 63 \\
\hline United Kingdom & 0.1075 & 23 & Chile & 0.0407 & 64 \\
\hline Canada & 0.1026 & 24 & Estonia & 0.0391 & 65 \\
\hline World & 0.0984 & & Hungary & 0.0387 & 66 \\
\hline
\end{tabular}




\begin{tabular}{cccccc}
\hline Senegal & 0.0971 & 25 & Japan & 0.0386 & 67 \\
Netherlands & 0.0949 & 26 & Latvia & 0.0385 & 68 \\
Georgia & 0.0924 & 27 & Cyprus & 0.0369 & 69 \\
Denmark & 0.0851 & 28 & Barbados & 0.0364 & 70 \\
Malaysia & 0.0845 & 29 & Moldova & 0.0331 & 71 \\
Belgium & 0.0773 & 30 & Uruguay & 0.0317 & 72 \\
Brazil & 0.0726 & 31 & Albania & 0.0313 & 73 \\
Spain & 0.0702 & 32 & Philippines & 0.0297 & 74 \\
Croatia & 0.0677 & 33 & Ireland & 0.0277 & 75 \\
Ukraine & 0.0662 & 34 & Zimbabwe & 0.0264 & 76 \\
Singapore & 0.0658 & 35 & Taiwan, China & 0.0253 & 77 \\
USA & 0.0652 & 36 & Cuba & 0.0244 & 78 \\
France & 0.0640 & 37 & Israel & 0.0244 & 79 \\
TFYR Macedonia & 0.0635 & 38 & Hong Kong & 0.0224 & 80 \\
South Africa & 0.0619 & 39 & Costa Rica & 0.0216 & 81 \\
Finland & 0.0582 & 40 & Paraguay & 0.0202 & 82 \\
Turkey & 0.0578 & 41 & Bangladesh & 0.0129 & 83 \\
\hline
\end{tabular}

Analyses of oil industry of similar countries, once again, show that Azerbaijan must develop its oil industry to export finished oil products to world markets. Azerbaijan, instead of exporting crude oil, can increase not only export of finished oil products also, petrochemical products such as lactams and lactones, tyres for bus or lorry, polyvinyl chloride.

Almost all similar countries are the biggest exporter of liquefied propane. Taking into account gas potentials of Azerbaijan this field should be developed in future.

The table shows that similar countries have a revealed advantage in products of the chemical sector. Sulphur (excluding, purified), nitrogenous fertilizers (this one indeed is in great demand in the country) photo film, should be produced in Azerbaijan in the near future. Azerbaijan has big potential for the development of this sector of economy.

Table 4. Detailed list of products in which similar countries currently have a revealed advantage, 2007-2009 average

\begin{tabular}{|c|c|c|c|c|c|c|c|c|c|c|c|c|c|c|c|c|}
\hline $\begin{array}{l}0 \\
0 \\
0 \\
0 \\
0 \\
0\end{array}$ & 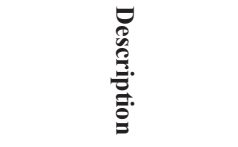 & 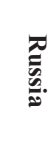 & $\stackrel{5}{\pi}$ & 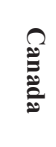 & 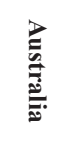 & $\frac{\Omega}{\stackrel{\varrho}{E}}$ & 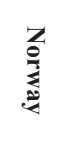 & 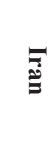 & $\begin{array}{l}\text { 펌 } \\
\stackrel{\Xi}{0} \\
\stackrel{0}{\varrho}\end{array}$ & 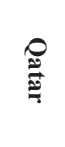 & 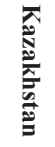 & 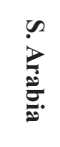 & $\begin{array}{l}\widehat{0} \\
\stackrel{3}{8} \\
\frac{0}{2} \\
\frac{0}{2}\end{array}$ & & 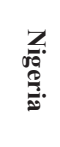 & 坣 \\
\hline 3421 & Liquefied propane & 1.13 & 2.95 & 4.93 & 3.61 & 0.27 & 8.47 & 5.98 & $\mathrm{n}$ & 29.74 & 1.93 & $\mathrm{n}$ & 0.00 & 63.23 & $\mathrm{n}$ & 8 \\
\hline 2512 & Mechanical wood pulp & 0.00 & 1.29 & 5.54 & 0.01 & 0.00 & 13.90 & 0.00 & $\mathrm{n}$ & 5.53 & $\mathrm{n}$ & $\mathrm{n}$ & 0.00 & 1.42 & 66.78 & 6 \\
\hline 3212 & Other coal & 3.30 & 0.03 & 1.29 & 29.15 & 23.81 & $\mathrm{n}$ & 0.03 & $\mathrm{n}$ & $\mathrm{n}$ & 7.07 & $\mathrm{n}$ & 2.35 & $\mathrm{n}$ & $\mathrm{n}$ & 6 \\
\hline 8911 & $\begin{array}{c}\text { Armoured Fighting } \\
\text { vehicle }\end{array}$ & 0.00 & 0.70 & 1.56 & 0.46 & 0.01 & 1.38 & 2.13 & $\mathrm{n}$ & 39.73 & $\mathrm{n}$ & 0.00 & 16.75 & $\mathrm{n}$ & 21.57 & 6 \\
\hline 430 & Barley grain & 2.95 & 1.05 & 1.82 & 12.43 & 0.00 & 0.00 & 0.00 & 0.01 & $\mathrm{n}$ & 7.57 & 0.00 & $\mathrm{n}$ & $\mathrm{n}$ & $\mathrm{n}$ & 5 \\
\hline 2239 & Oil seed/etc flour/meal & 0.19 & 0.39 & 0.37 & 1.01 & 0.32 & 0.00 & 0.01 & 0.04 & 8.79 & 2.37 & 0.00 & 12.46 & $\mathrm{n}$ & 2.86 & 5 \\
\hline 2462 & $\begin{array}{l}\text { Woodwaste (incl } \\
\text { sawdust) }\end{array}$ & 0.48 & 1.66 & 6.36 & 0.14 & 0.00 & 0.49 & 0.00 & 0.01 & 2.12 & 0.01 & 0.00 & 0.00 & 1.22 & 53.06 & 5 \\
\hline 2473 & Wood poles, Treated & 0.26 & 1.76 & 3.84 & 0.64 & 0.24 & 0.85 & $\mathrm{n}$ & 1.92 & 13.10 & 0.00 & $\mathrm{n}$ & 0.00 & 2.05 & 25.79 & 5 \\
\hline 2483 & $\begin{array}{c}\text { Softwood } \\
\text { shaped/grooved }\end{array}$ & 0.36 & 1.18 & 3.61 & 0.25 & 0.09 & 0.49 & 0.00 & 0.49 & 8.35 & 0.02 & 0.03 & 0.00 & 4.26 & 44.01 & 5 \\
\hline 2485 & $\begin{array}{c}\text { Hardwood } \\
\text { shaped/grooved }\end{array}$ & 0.07 & 0.73 & 1.03 & 0.12 & 0.82 & 0.16 & 0.00 & 1.27 & 8.09 & 0.00 & 0.01 & 0.00 & 1.72 & 10.21 & 5 \\
\hline 2683 & Animal hair uncomb & 0.21 & 2.15 & 0.11 & 0.99 & 0.00 & 0.00 & 9.53 & $\mathrm{n}$ & 160.9 & 1.51 & 0.06 & $\mathrm{n}$ & $\mathrm{n}$ & 52.35 & 5 \\
\hline 2721 & $\begin{array}{c}\text { Animal,veg fertilizer } \\
\text { crude }\end{array}$ & 0.08 & 0.74 & 0.56 & 0.65 & 1.10 & 2.58 & 0.23 & 0.32 & 23.16 & 0.00 & 3.94 & 0.18 & $\mathrm{n}$ & 9.90 & 5 \\
\hline 2741 & Sulphur exc. Purified & 5.96 & 2.55 & 4.18 & 0.03 & 0.19 & 0.00 & 2.22 & $\mathrm{n}$ & 6.11 & 0.03 & 0.68 & 0.00 & $\mathrm{n}$ & 0.75 & 5 \\
\hline
\end{tabular}




\begin{tabular}{|c|c|c|c|c|c|c|c|c|c|c|c|c|c|c|c|c|}
\hline 5621 & Nitrogenous Fertilizers & 7.23 & 0.17 & 2.29 & 0.44 & 0.07 & 0.00 & 0.22 & 0.00 & 27.24 & 0.01 & 4.56 & 1.67 & 0.91 & $\mathrm{n}$ & 5 \\
\hline 6412 & Uncoated Paper/board & 0.64 & 1.67 & 2.56 & 0.64 & 1.30 & 2.64 & 0.00 & 0.01 & 13.52 & 0.00 & 0.01 & 0.09 & 0.00 & 0.00 & 5 \\
\hline 8824 & $\begin{array}{c}\text { Photographic paper } \\
\text { unexp }\end{array}$ & 0.04 & 1.62 & 0.92 & 4.18 & 0.10 & 0.01 & $\mathrm{n}$ & $\mathrm{n}$ & 49.98 & 0.00 & 0.00 & 0.00 & 55.26 & 7.60 & 5 \\
\hline 8825 & $\begin{array}{c}\text { Photo film/plates } \\
\text { undevd }\end{array}$ & 0.01 & 0.44 & 0.40 & 1.16 & 0.09 & 4.08 & $\mathrm{n}$ & 0.11 & 28.46 & $\mathrm{n}$ & 0.03 & 0.03 & 7.14 & 1.30 & 5 \\
\hline 8912 & $\begin{array}{c}\text { Bombs/ammunition/ } \\
\text { etc }\end{array}$ & 4.31 & 0.15 & 0.29 & 0.28 & 0.01 & 2.48 & 0.65 & $\mathrm{n}$ & 42.27 & $\mathrm{n}$ & 0.00 & 26.27 & $\mathrm{n}$ & 38.55 & 5 \\
\hline 471 & $\begin{array}{l}\text { Cereal flour } \\
\text { (non-wheat) }\end{array}$ & 0.09 & 0.25 & 0.57 & 2.04 & 2.02 & 0.03 & 0.01 & 6.01 & $\mathrm{n}$ & 0.07 & 0.01 & 7.13 & 0.00 & 0.00 & 4 \\
\hline 616 & Natural honey & 0.03 & 0.44 & 1.43 & 2.73 & 0.04 & 0.02 & 1.78 & 0.13 & 0.01 & 0.04 & 0.48 & 0.00 & $\mathrm{n}$ & 1.10 & 4 \\
\hline 619 & Sugars net/syrups/etc. & 0.08 & 1.48 & 1.65 & 0.35 & 2.24 & 0.05 & 0.04 & 0.00 & $\mathrm{n}$ & 0.00 & 0.01 & 0.08 & 0.00 & 7.53 & 4 \\
\hline 2322 & $\begin{array}{c}\text { Reclaimed/waste } \\
\text { rubber }\end{array}$ & 0.39 & 3.12 & 2.30 & 0.20 & 0.26 & 0.02 & 0.12 & 0.08 & 13.24 & $\mathrm{n}$ & 0.20 & 0.08 & $\mathrm{n}$ & 12.15 & 4 \\
\hline 2687 & $\begin{array}{c}\text { Combed/carded } \\
\text { wool/hair }\end{array}$ & 0.01 & 0.15 & 2.44 & 12.57 & 0.00 & 0.00 & 0.68 & $\mathrm{n}$ & 16.10 & 0.08 & 0.00 & 0.00 & $\mathrm{n}$ & 9.29 & 4 \\
\hline 2878 & Mo/nb/v/ta/ti/zrore/con & 1.07 & 0.29 & 1.72 & 9.28 & 0.00 & 0.00 & 3.48 & 0.00 & $\mathrm{n}$ & $\mathrm{n}$ & 0.31 & 0.00 & 0.00 & 0.95 & 4 \\
\hline 3432 & Natural gas, Gaseous & 21.40 & 0.45 & 6.86 & 0.00 & 0.04 & 14.34 & $\mathrm{n}$ & $\mathrm{n}$ & $\mathrm{n}$ & 0.85 & $\mathrm{n}$ & $\mathrm{n}$ & 18.96 & $\mathrm{n}$ & 4 \\
\hline 5156 & Lactams/Lactones & 1.70 & 0.34 & 0.02 & 0.05 & 1.02 & 0.02 & 0.03 & 0.00 & 18.99 & $\mathrm{n}$ & 0.00 & 0.00 & $\mathrm{n}$ & 7.71 & 4 \\
\hline 5731 & Polyvinyl chloride & 1.47 & 0.35 & 0.83 & 0.08 & 6.74 & $\mathrm{n}$ & 0.97 & 0.20 & $\mathrm{n}$ & 0.00 & 1.04 & 1.43 & 0.00 & $\mathrm{n}$ & 4 \\
\hline 6252 & Tyres,new,bus or lorry & 0.85 & 1.21 & 0.85 & 0.12 & 2.52 & 0.01 & 0.31 & 1.30 & 21.95 & 0.01 & 0.00 & 0.17 & 0.00 & $\mathrm{n}$ & 4 \\
\hline 6411 & Newsprint Rolls/sheets & 2.72 & 3.29 & 7.00 & 0.01 & 0.00 & $\mathrm{n}$ & 0.00 & 0.00 & 1.58 & 0.00 & 0.00 & 0.00 & $\mathrm{n}$ & $\mathrm{n}$ & 4 \\
\hline 6564 & Tulles/nets/laces & 0.00 & 0.01 & 0.01 & 0.06 & 2.58 & 0.00 & 5.49 & 0.05 & 9.03 & 0.01 & 0.00 & 0.00 & $\mathrm{n}$ & 3.39 & 4 \\
\hline 6638 & Asbestosmanufactures & 1.65 & 1.18 & 0.90 & 0.55 & 5.37 & 0.02 & 0.07 & 0.47 & 34.37 & 0.00 & 0.14 & 0.20 & 0.00 & $\mathrm{n}$ & 4 \\
\hline 7931 & Yachts/pleas.Vessels & 0.03 & 1.73 & 0.84 & 1.19 & 0.04 & 0.95 & 0.00 & 0.00 & 49.16 & 0.00 & 0.00 & 0.00 & $\mathrm{n}$ & 21.68 & 4 \\
\hline 8413 & $\begin{array}{c}\text { M/b jackets/blazer } \\
\text { woven }\end{array}$ & 0.10 & 0.40 & 0.20 & 0.05 & 4.80 & 0.04 & 0.05 & 1.05 & 3.00 & $\mathrm{n}$ & 0.00 & 0.29 & $\mathrm{n}$ & 2.68 & 4 \\
\hline 8456 & Swimwear & 0.03 & 1.20 & 0.61 & 0.29 & 4.15 & 0.02 & 0.00 & 1.18 & 9.57 & 0.00 & 0.00 & 0.02 & $\mathbf{n}$ & 8.27 & 4 \\
\hline
\end{tabular}

Ranking* - shows the number of countries which currently have a revealed advantage in the product.

$\mathrm{n}$ - There is no export of certain product from the country in the years 2007-2009.

There are also some products like newsprint rolls and sheets, chemical wood pulp, mechanical wood pulp, wood waste, wood pole, softwood (shaped), uncoated paper, photographic paper, coal, which are not corresponding with natural potential of Azerbaijan. Traditionally, Azerbaijan imports these products.

Woven jackets, blazers, swimwear, hat shapes and other products of textile industry might be developed in the near future, too. At the same time, potential of cotton and wool industry should be used for this reason.

We find out from the detailed analysis of export structure of other countries also that Azerbaijan should be able to export oil seeds, flour and meal, barley grain, fine animal hair, salted, frozen, preserved and dried fish liver, not frozen crustaceans, cereal (non-wheat) flour, cereal meal, cereals breakfast foods, sugars, syrups, malt, malt flour, natural honey, combed and carded wool. At present, Azerbaijan exports other agricultural products to world market even in small quantities. All products, which are chosen from the export list of similar countries for Azerbaijan, are corresponding to the natural and economic potentials of Azerbaijan.

\section{Conclusions}

The results of these analyses have been taken into consideration during preparation of Employment Strategy Paper. Computation of Balassa RCA indices for Azerbaijan showed that some products of agriculture (tobacco, apple, nuts, tea, vegetables, oilseeds, raw cotton, and pharmaceutical plants growing) and processing (fruit juices, cigarettes, manufactured tobacco, animal skins, cotton linters, carded and combed cotton, cotton seed oil, safflower oil), oil industry (kerosene and medium oils, motor spirit and light oils, gas oils, fuel oils), chemical and petrochemical industry (ethylene, polyacetals and polyethers, polyethylene and plastics) have a very big potential. Government policy must support the development of these sectors which are competitive in world markets and will be the key sectors in the creation of new jobs.

It has been accepted that creating an enabling environment for the development of both business and employment is a key feature of the employment strategy. In large measure this requires the identification of the 
constraints which prevent the development of the private sector and implementing measures to overcome these constraints. That is, it must address those constraints which prevent or inhibit competitive industries developing.

This study shows that competitive (non-oil) sectors do exist in Azerbaijan and that there are good grounds to suppose that new and competitive industries could develop in the future. This is not to say that such enterprises could or should be developed through the creation of new state owned enterprises or through an interventionist strategy. Such policy approaches would be far more likely to reduce rather than increase competitiveness.

In contrast, our first key recommendation is that the government undertakes a careful and detailed analysis of those sectors which are shown to currently be competitive in Azerbaijan with a view to identifying the key obstacles which prevent these sectors from increasing further their exports. This analysis should cover both constraints in supplying export markets (such as protectionism in export markets, lack of market intelligence, customs procedures and transport infrastructure) and constraints affecting production (for example, excessive regulation, monopoly power, requirements for skilled labor, finance).

Our second key recommendation is that the government undertakes a similar detailed analysis of those sectors which are shown to be a current source of advantage in similar countries but do not reveal an advantage for Azerbaijan. Here the key question that needs to be addressed is: "Since these are currently exporting sectors in similar countries why is it that neither domestic nor foreign investors have invested in developing these in Azerbaijan?" Like the analysis of the existing sectors, this would need to identify the key constraints. However, this analysis would need to be broader in scope and include, for example, the information available to potential investors.

We would further recommend that once the government has identified the key constraints, it acts to remove these. For example, if it is found that Azerbaijan's exports are blocked by protectionism in export markets, then the Government of Azerbaijan should open discussions with key foreign governments for the removal of trade barriers. Likewise, if a lack of information on export opportunities proves a key constraint, then it should develop effective export market intelligence services.

We strongly suggest that more detailed analyses should be done for the computation of export similarities. It should be reasonable to carry out same type research for the non - oil sector (excluding oil sector). Potentials of the service sector (especially, transit potential) must be carefully researched in order to find out other possibilities for job creation. As well, some non-oil sectors which could be developed on the base of natural and economic potential of the country have to be researched too. We believe that this study has made a valuable contribution to the development of an employment strategy by drawing attention to the need to encourage a competitive private sector and, hence, a sustainable increase in employment. However, this study focused on competitiveness by industry and did not directly link competitiveness to labor markets.

It is suggested that further research is needed to provide a basis for linking industrial competitiveness to labor markets. Such research may add to the factor content model and must address following questions:

$>$ To what extent do different types of labor (skilled or unskilled) provide a source of advantage for Azerbaijan at present?

$>$ What industries in other countries make intensive use of the types of labor that provide a basis for Azerbaijan's current advantages?

$>$ How would increased openness to competition and trade be likely to affect the demand for different types of labor in Azerbaijan?

\section{References}

Balassa, B. (1965). Trade Liberalisation and "Revealed Comparative Advantage". The Manchester School of Economic and Social Studies, 33, 99-123. http://dx.doi.org/10.1111/j.1467-9957.1965.tb00050.x

Ballance, R., Forstner, H., \& Murray, T. (1986). More on Measuring Comparative Advantage: A Reply. Weltwirtschaftliches Archiv, 122, 375-378. http://dx.doi.org/10.1007/BF02705752

Brander, J. A., \& Paul, K. (1983). A Reciprocal Dumping Model of International Trade. Journal of International Economics, 15, 313-321. http://dx.doi.org/10.1016/S0022-1996(83)80008-7

Davies, D. (1995). Intra-industry trade: a Heckscher-Ohlin-Ricardo approach. Journal of International Economics, 39, 201-26. http://dx.doi.org/10.1016/0022-1996(95)01383-3

Falvey, R. E. (1981). Commercial Policy and Intra-Industry Trade. Journal of International Economics, 11(4), 495-511. http://dx.doi.org/10.1016/0022-1996(81)90031-3 
Heckscher, E. (1919). The Effects of Foreign Trade on the Distribution of Income. Ekonomisk Tidskrift, 21, 497-512.

Krugman, P. (1979). Increasing returns, monopolistic competition, and international trade. Journal of International Economics, 9(4), 469-479. http://dx.doi.org/10.1016/0022-1996(79)90017-5

Lancaster, K. (1980). Intra-industry trade under perfect monopolistic competition. Journal of International Economics, 10, 151-175. http://dx.doi.org/10.1016/0022-1996(80)90052-5

Ohlin, B. (1933). Interregional and International Trade. Cambridge MA: Harvard Univ. Press.

Ricardo, D. (1817). Principles of Economy and Taxation.

Smith, A. (1766). The Wealth of Nations. Reprinted as E. Cannan (Ed.) in 1961, London: Methuen.

Webster, A. (1993). The skill and higher educational content of UK trade. Oxford Bulletin of Economics and Statistics, 55, 141-60. http://dx.doi.org/10.1111/j.1468-0084.1993.mp55002001.x

Webster, A., \& Hardwick, P. (2005). International trade in financial services. The Service Industries Journal, 25(6), 721-746. http://dx.doi.org/10.1080/02642060500103266

\section{Copyrights}

Copyright for this article is retained by the author(s), with first publication rights granted to the journal.

This is an open-access article distributed under the terms and conditions of the Creative Commons Attribution license (http://creativecommons.org/licenses/by/3.0/). 